Determination of Background Uranium Concentration in the Snake River Plain Aquifer under the Idaho National Engineering and Environmental Laboratory's Radioactive Waste Management Complex

Molly K. Leecaster

L. Don Koeppen

Gail L. Olson

June 2003

Idaho National Engineering and Environmental Laboratory Bechtel BWXT Idaho, LLC 


\title{
Determination of Background Uranium Concentration in the Snake River Plain Aquifer under the Idaho National Engineering and Environmental Laboratory's Radioactive Waste Management Complex
}

\author{
Molly K. Leecaster \\ L. Don Koeppen \\ Gail L. Olson
}

June 2003
Idaho National Engineering and Environmental Laboratory Idaho Completion Project Idaho Falls, Idaho 83415

Prepared for the

U.S. Department of Energy

Assistant Secretary for Environmental Management

Under DOE Idaho Operations Office

Contract DE-AC07-99ID13727 


\begin{abstract}
Uranium occurs naturally in the environment and is also a contaminant that is disposed of at the Radioactive Waste Management Complex (RWMC) at the Idaho National Engineering and Environmental Laboratory. To determine whether uranium concentrations in the Snake River Plain Aquifer, which underlies the laboratory, are elevated as a result of migration of anthropogenic uranium from the Subsurface Disposal Area in the RWMC, uranium background concentrations are necessary. Guideline values are calculated for total uranium, ${ }^{234} \mathrm{U}$, ${ }^{235} \mathrm{U}$, and ${ }^{238} \mathrm{U}$ from analytical results from up to five datasets. Three of the datasets include results of samples analyzed using isotope dilution thermal ionization mass spectrometry (ID-TIMS) and two of the datasets include results obtained using alpha spectrometry. All samples included in the statistical testing were collected from aquifer monitoring wells located within 10 miles of the RWMC. Results from ID-TIMS and alpha spectrometry are combined when the data are not statistically different. Guideline values for total uranium were calculated using four of the datasets, while guideline values for ${ }^{234} \mathrm{U}$ were calculated using only the alpha spectrometry results (2 datasets). Data from all five datasets were used to calculate ${ }^{238} \mathrm{U}$ guideline values. No limit is calculated for ${ }^{235} \mathrm{U}$ because the ID-TIMS results are not useful for comparison with routine monitoring data, and the alpha spectrometry results are too close to the detection limit to be deemed accurate or reliable for calculating a ${ }^{235} \mathrm{U}$ guideline value. All guideline values presented represent the upper $95 \%$ coverage $95 \%$ confidence tolerance limits for background concentration. If a future monitoring result is above this guideline, then the exceedance will be noted in the quarterly monitoring report and assessed with respect to other aquifer information. The guidelines (tolerance limits) for total $\mathrm{U},{ }^{234} \mathrm{U}$, and ${ }^{238} \mathrm{U}$ are $2.75 \mathrm{pCi} / \mathrm{L}$, $1.92 \mathrm{pCi} / \mathrm{L}$, and $0.90 \mathrm{pCi} / \mathrm{L}$, respectively.
\end{abstract}




\section{CONTENTS}

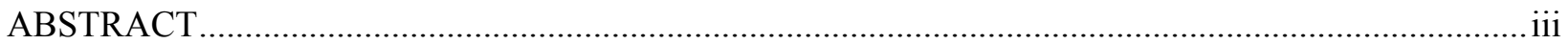

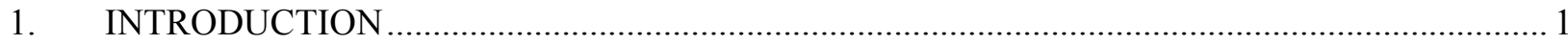

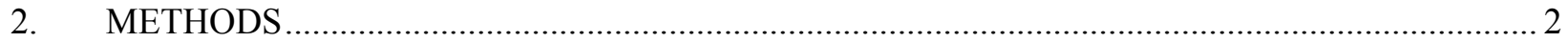

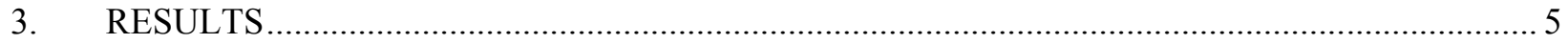

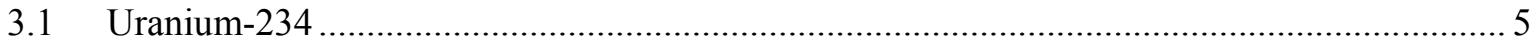

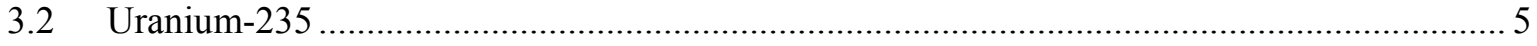

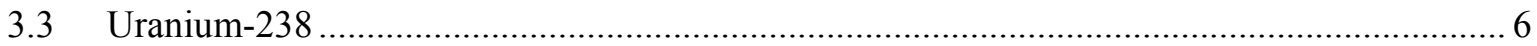

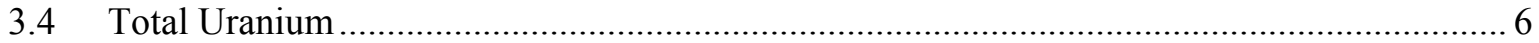

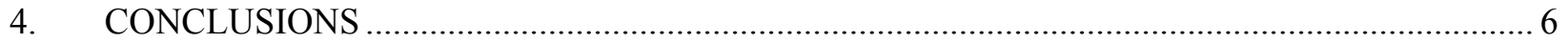

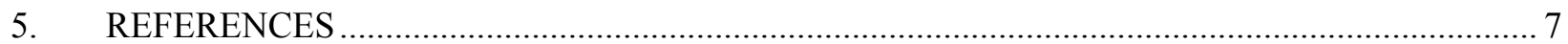

FIGURES

Figure 1. Snake River Plain Aquifer sampling wells within 10 miles of the INEEL's RWMC............... 11

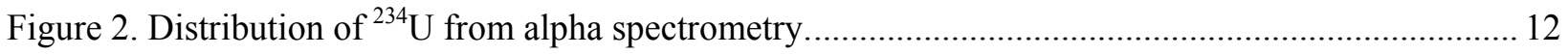

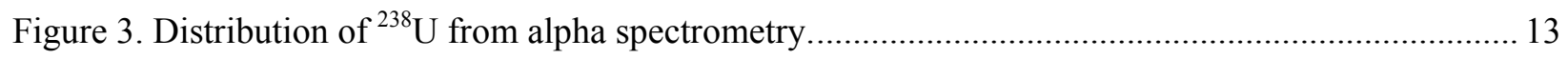

\section{TABLES}

Table 1. Sample size (n), mean $(\bar{x})$, and standard deviation (s) for total uranium and isotopes (p-value from Kruskal-Wallis test for differences among wells) from routine monitoring wells analyzed by alpha spectrometry (dataset 1)

Table 2. Sample size (n), mean ( $\bar{x}$ ), and standard deviation (s) for total uranium and isotopic results for each dataset, and the resulting guideline values ${ }^{\mathrm{a}}$ derived by combining appropriate datasets. ........ 10 


\section{Determination of Background Uranium Concentration in the Snake River Plain Aquifer under the Idaho National Engineering and Environmental Laboratory's Radioactive Waste Management Complex}

\section{INTRODUCTION}

A background concentration for uranium and its isotopes is needed in order to determine if uranium has contaminated the Snake River Plain Aquifer (SRPA) under the Idaho National Engineering and Environmental Laboratory (INEEL) Radioactive Waste Management Complex (RWMC). Future groundwater sample results that exceed the expected background range for total uranium or any isotope will be cause for investigation.

Uranium is naturally occurring in the environment, and detection of uranium is, in itself, not cause for alarm. Because uranium-bearing wastes have been disposed of in the Subsurface Disposal Area (SDA) at the RWMC since the $1950 \mathrm{~s}$, there is a potential for contaminant release into the environment and a need to be able to detect a release should one occur. The U.S. Geological Survey (USGS) published a background concentration range for total uranium in the Snake River Plain Aquifer (SRPA) (Knobel, Orr, and Cecil, 1992); however, background ranges for the individual uranium isotopes are needed as well to distinguish elevated isotopic levels during routine RWMC aquifer monitoring, if and when they occur. Even the total uranium data from the USGS data are of limited value at the SDA because the samples were collected from wells near the southern INEEL boundary up to 110 miles downgradient of the INEEL. Roback et al (2001) demonstrated that there is substantial spatial variation in the aquifer. Thus, levels in the Magic Valley area are probably not representative of the aquifer at the RWMC. Various factors affect uranium background concentrations, including the age and flow rate of the aquifer at a particular location, thus, it was desirable to obtain local background uranium isotopic limits for the RWMC area.

Establishing background uranium concentrations for the RWMC area is complicated by the lack of pre-disposal aquifer monitoring data and the need for a relatively large dataset in order to achieve reasonable precision and produce a meaningful background limit. Even though no pre-disposal data are available, Roback et al (2000 and 2001) verify that the aquifer in the area of the RWMC has not likely been affected by anthropogenic uranium contamination. A large dataset was obtained by combining five datasets. The samples for datasets were collected at different temporal and spatial scales and analyzed with two different analytical methods. Only well samples within 10 miles of the RWMC were considered.

We use all five datasets to investigate background concentrations for isotopic and total uranium. Analyses are done to determine comparability of the analysis methods and similarity of the datasets. The resulting datasets are used to calculate the appropriate background concentrations for use in an aquifer monitoring program for the RWMC. 


\section{METHODS}

Five datasets were used to calculate background aquifer uranium levels for the RWMC area (Figure 1).

1. Waste Area Group (WAG) 7 quarterly groundwater monitoring analysis data (Holdren et al 2002 and Olson et al 2003): There were 219 results for ${ }^{234} \mathrm{U}, 127$ results for ${ }^{235} \mathrm{U}$, and 223 results for ${ }^{238} \mathrm{U}$ from 16 RWMC monitoring wells sampled from 1998 through 2002. Quarterly monitoring samples were analyzed for uranium isotopes using alpha spectrometry.

2. WAG 7 alpha spectrometric screening analyses for a uranium and plutonium of the aquifer on and near the INEEL: Thirty-seven aquifer wells were sampled for the uranium and plutonium background study in 1999, and 12 of the samples, designated for alpha spectrometry analysis, were obtained within 10 miles of the RWMC.

3. WAG 7 isotope dilution thermal ionization mass spectrometry (ID-TIMS) analysis for the uranium and plutonium background study of the aquifer on and near the INEEL (Roback 2002): Thirtyseven aquifer wells were sampled for the uranium and plutonium background study in 1999. These data were part of the same 1999 WAG 7 uranium and plutonium background study discussed in item 2 above, but analyzed for extremely low levels using ID-TIMS. There were ten samples collected within 10 miles of the RWMC and analyzed by ID-TIMS. Six of these special study samples, collected within 10 miles of the RWMC, were analyzed by using both alpha spectrometry and TIMS.

4. Los Alamos National Laboratory (LANL) groundwater flow patterns study (Roback et al 2001): This dataset was obtained through an independent study conducted by LANL to investigate chemical evolution and flow patterns in the eastern SRPA. Fifty-six aquifer wells were sampled for the SRPA study between 1996 and 1998, and 22 were collected from wells within 10 miles of the RWMC, and analyzed for uranium and its isotopes using ID-TIMS.

5. LANL uranium and plutonium special aquifer study at the RWMC using ID-TIMS (Roback et al 2000): This study assessed uranium and plutonium in the aquifer beneath the SDA within the RWMC. The SDA study data were collected in 1999 from 9 aquifer-monitoring wells within an approximate 1-mile radius of the RWMC. For both LANL studies, total uranium and uranium isotopic ratios were measured using ID-TIMS. Altogether, there were up to 276 results for a given isotope collected from up to 60 wells within 10 miles of the RWMC.

To use the data from the ID-TIMS analysis, it was necessary to first calculate the isotopic values from the reported data. The ID-TIMS data were measured as ${ }^{238} \mathrm{U} /{ }^{234} \mathrm{U}$ ratio of isotopes measured in ppm and total $\mathrm{U}(\mathrm{ppb})$. The isotope values (atoms $/ \mathrm{Kg}$ ) were calculated as

$$
\begin{aligned}
{ }^{234} U_{(\text {atoms } / K g)} & =\frac{U_{(p p b)} \times A \times A F_{234} \times \frac{{ }^{234} U /{ }^{238} U_{(p p m)}}{1,000,000}}{1,000,000 \times M \times \frac{\lambda_{238}}{\lambda_{234}}}, \\
{ }^{235} U_{(\text {atoms } / K g)} & =\frac{U_{(p p b)} \times A \times A F_{235}}{1,000,000 \times M}, \text { and }
\end{aligned}
$$




$$
{ }^{238} U_{(\text {atoms } / K g)}=\frac{U_{(p p b)} \times A \times A F_{238}}{1,000,000 \times M}
$$

where $A$ is Avagadro's number, $A F_{x}$ is the atomic fraction (isotopic abundance found in nature) for isotope $x, M$ is the atomic mass of the isotope (e.g., 238.029 for ${ }^{238} \mathrm{U}$ ) and $\lambda_{x}$ is the decay constant which is the fractional rate of decrease in activity of an isotope due to radioactive decay (natural $\log$ of 2 divided by the half-life of the isotope). These ID-TIMS data were transformed to activity ( $\mathrm{pCi} / \mathrm{L}$ ) before statistical analyses as

$$
{ }^{x} U_{(p C i / L)}=\frac{{ }^{x} U_{(a t o m s / K g)} \lambda_{x}}{C}
$$

where $C$ is the conversion from picocuries to disintegrations per year (dpy) and $x$ is either 234, 235, or 238 . The alpha spectrometry data were reported in activity $(\mathrm{pCi} / \mathrm{L})$ for each isotope, so no transformation was necessary.

Total uranium was measured directly by ID-TIMS, but not by alpha spectrometry. Total uranium was calculated as the sum of the three isotopes for both analytical methods for use in statistical analysis.

Measurement methods for uranium include a sample-specific uncertainty. The measurement uncertainty indicates the precision attained for that result. Measurement uncertainties were used in comparison between ID-TIMS and alpha spectrometry datasets.

For our alpha spectrometry data, the laboratory reported the measurement uncertainties for each isotopic result. For the ID-TIMS data, uncertainties were reported for the total $U(p p b)$ and ${ }^{238} U /{ }^{234} U$ ratio of isotopes measured in ppm. The ID-TIMS uncertainties for ${ }^{234} \mathrm{U},{ }^{235} \mathrm{U}$, and ${ }^{238} \mathrm{U}$ (in pCi/L) were calculated as

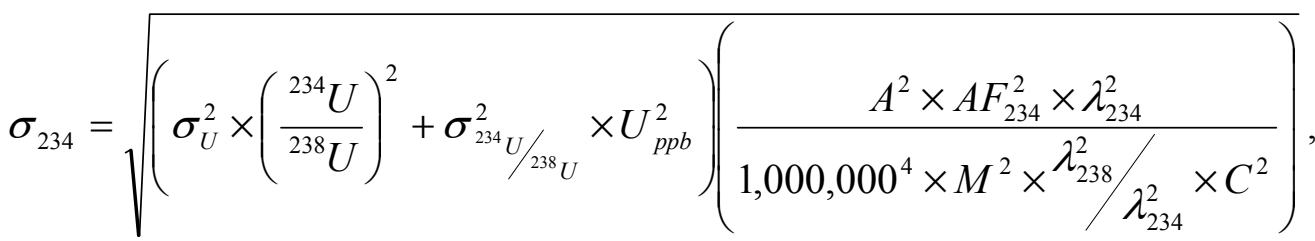

$$
\begin{aligned}
& \sigma_{235}=\sqrt{\frac{\sigma_{U}^{2} \times A^{2} \times A F_{233}^{2} \times \lambda_{235}^{2}}{1,000,000^{2} \times M^{2}} / C^{2}} \text {, and } \\
& \sigma_{238}=\sqrt{\frac{\sigma_{U}^{2} \times A^{2} \times A F_{238}^{2} \times \lambda_{238}^{2}}{1,000,000^{2} \times M^{2}} / C^{2}},
\end{aligned}
$$

where components are as defined above.

There were many duplicate alpha spectrometry analyses conducted on aquifer samples. Usually, the second result was a re-analysis of a separate subsample of the groundwater following an initial detection on the first subsample. These results were not independent. Non-independent values result in an underestimate of variance, which biases hypothesis tests and estimation procedures. Independence of results is a key assumption for testing and estimation methods. Each dataset was reduced to one result per date per well. The weighted mean of the re-analysis results was used, where the weighting factor was the 
inverse of the sample-specific uncertainty. Thus, results with greater uncertainty (i.e., less precision) received less weight.

For dataset 1 , tests were conducted to determine if there were any temporal trends or significant differences among wells. Lack of such patterns would support the assumption that the data were from the same population and thus, could be combined. The temporal trend was assessed for each well using Kendall's nonparametric test. Kendall's test was used because the sample sizes were too small to determine a reasonable distribution for all wells. Trend was assessed to provide evidence that status was not changing and that data across years could be combined to determine background status. There were from 6 to 17 consecutive sample dates per well that could be used to determine temporal trend. Differences among wells in dataset 1 were tested to determine if significant spatial trends existed in the monitoring area. Because sample sizes within wells were small, nonparametric Kruskal-Wallis tests were performed. If well medians were significantly different, multiple comparisons using Tukey's method were made to determine which wells were significantly different. Tukey's method controls the overall false positive decision error rate when making many non-independent pair-wise comparisons.

There were six samples taken from the WAG 7 plutonium background study of the aquifer that were split and analyzed by both alpha spectrometry (dataset 2) and ID-TIMS (dataset 3). These results were tested using the nonparametric Wilcoxon signed rank test for paired data. If comparability could not be asserted then the datasets from the different methods were not combined.

Up to five datasets were tested for similarity before being combined. Datasets from different analysis methods were combined only if the means or medians and the variances were not significantly different. Each dataset was tested for normality using the Kolmogorov-Smirnov (K-S) test, which is sensitive to departures from normality due to long distribution tails (extreme high and low values) that might inflate variance and thus the background status. The K-S test assumes the data are independent, but makes no distribution assumptions. Analysis of variance (ANOVA) was used to test differences in means for normally distributed datasets, and the Kruskal-Wallis test was used if the distributions were nonnormal. The ANOVA assumes the data are normally distributed with common variance among groups. If significant differences existed, then pair-wise comparisons were made using Tukey's method and t-tests for the normal case and Wilcoxon tests for the non-normal case. Variances of the datasets were tested for differences using Levene's test. This is a test for equality among 2 or more groups.

Tolerance limits were calculated for each uranium isotope using the combination of the appropriate datasets, as defined from the analyses above. The tolerance limit is calculated as

$T L=\bar{x}+c_{p, \alpha, n} \sqrt{\sigma^{2}+s^{2}}$,

where $\bar{x}$ is the mean, $c$ is a tabled value that depends on the chosen percentile $\left(p=95^{\text {th }}\right)$, the confidence $(1-\alpha=95 \%)$, and the sample size $n, \sigma^{2}$ is the squared average uncertainty, and $s^{2}$ is the sample variance. 


\section{RESULTS}

The following discussion identifies how the datasets were combined to derive the concentration guidelines for ${ }^{234} \mathrm{U},{ }^{235} \mathrm{U},{ }^{238} \mathrm{U}$ and total uranium.

\subsection{Uranium-234}

For the routine monitoring alpha spectrometry results (dataset 1), there were no temporal trends of

${ }^{234} \mathrm{U}$ in any of the wells (Kendall p-values $>0.1$ ), but there were some significant differences of the means among wells. Multiple comparisons revealed a lower ${ }^{234} \mathrm{U}$ concentration group (M4D, M10S and M1S), and a higher concentration group (all other wells) (Figure 2). The lower concentration group wells are located close together just southwest of the SDA (Figure 1).

The distribution of the alpha spectrometry data (datasets 1 and 2) was non-normal (K-S p-value $<$ 0.0001), so a Wilcoxon rank sum test was used to test for differences between medians. The medians of the alpha spectrometry datasets 1 and 2 were not significantly different using the Wilcoxon rank sum test $(p$-value $=0.4)$, and neither were the variances (Levene's p-value $=0.7)$.

For the analytical methods comparison, paired results from datasets 2 and 3 (ID-TIMS and alpha spectrometry) were significantly different using the Wilcoxon signed rank test ( $p$-value $=0.02$ ). ID-TIMS is 10 times more sensitive than is alpha spectrometry.

The two alpha spectrometry datasets (1 and 2) were combined to establish the ${ }^{234} \mathrm{U}$ aquifer guideline. The upper $95 \%$ confidence $95^{\text {th }}$ percentile tolerance limit for ${ }^{234} \mathrm{U}$ is $1.92 \mathrm{pCi} / \mathrm{L}$. The datasets were combined (Table 2), and the overall distribution of the data was non-normal (K-S p-value $<0.0001)$.

\subsection{Uranium-235}

For the routine monitoring alpha spectrometry results (dataset 1), there were no temporal trends of ${ }^{235} \mathrm{U}$ in any of the wells (Kendall $\mathrm{p}$-values $>0.1$ ). The distribution of both alpha spectrometry datasets (datasets 1 and 2) was non-normal (K-S p-value $<0.0001$ ), so a Wilcoxon rank sum was used to test for differences between medians. The medians were not significantly different ( $p$-value $=0.2)$ but the variances were significantly different (Levene's $p$-value $=0.01$ ), therefore the ${ }^{235} \mathrm{U}$ data from the two alpha spectrometry datasets were not combined (Table 2).

For the analytical methods comparison, paired results from datasets 2 and 3 (alpha spectrometry and ID-TIMS) were significantly different using the Wilcoxon signed rank test ( $\mathrm{p}$-value $=0.02)$. The significant difference may be due, in part, to the alpha spectrometry results being very close to the detection limit. A detectable result is defined as a measured result greater than its $3 \sigma$ uncertainty and greater than its MDA (minimum detectable activity). The alpha spectrometry ${ }^{235} \mathrm{U}$ results $\leq 3 \sigma$ (i.e., nondetects) ranged from 0 to 0.078 , with a median of 0.021 . The $>3 \sigma$ results (i.e., positive detections) for ${ }^{235} \mathrm{U}$ from alpha spectrometry ranged from 0.01 to 0.296 , with a median of 0.046 . Thus, the detectable and nondetectable results had overlapping ranges, in comparison to the detection sensitivities achievable by ID-TIMS. ID-TIMS analysis was approximately 10 times more sensitive than can be achieved using alpha spectrometry. A common method of reporting uncertainty is as percent of concentration. For ${ }^{235} \mathrm{U}$, the measurement uncertainty at the $95 \%$ confidence level was approximately $65 \%$ of the concentration for alpha spectrometry, but only $0.29 \%$ for ID-TIMS.

For the above reasons, limits based on the alpha spectrometry data are not useful for defining background for ${ }^{235} \mathrm{U}$. Since the detection limits achievable by ID-TIMS analysis are not possible with the 
routine WAG 7 analysis method of alpha spectrometry, a limit based on those results is not useful either. Thus, no background limit is set for ${ }^{235} \mathrm{U}$ based on our current uranium analysis data.

\subsection{Uranium-238}

For the routine monitoring alpha spectrometry results (dataset 1), there were no temporal trends of ${ }^{238} \mathrm{U}$ in any of the wells (Kendall p-values $>0.1$ ), but there were some significant differences among wells. As in the case for ${ }^{234} \mathrm{U}$, multiple comparisons revealed a lower concentration group consisting of wells M4D, M10S, and M1S, and a higher concentration group (all other wells) (Figure 3). The lower concentration group wells are located close together just southwest of the SDA (Figure 1).

For the analytical methods comparison, paired results from datasets 2 and 3 (ID-TIMS and alpha spectrometry) were not significantly different using the Wilcoxon signed rank test ( $p$-value $=0.6)$. The alpha spectrometry data from routine monitoring was non-normal for ${ }^{238} \mathrm{U}(\mathrm{K}-\mathrm{S} \mathrm{p}$-value $<0.0001)$, so a Kruskal-Wallis test was used to test the medians of the five datasets. The medians were similar across datasets $(p$-value $=0.4)$, as were the variances (Levene's $p$-value $=0.3$ ).

Because the results among datasets were not significantly different, all five datasets were combined to derive a concentration guideline for ${ }^{238} \mathrm{U}$ (Table 2). The upper $95 \%$ confidence $95^{\text {th }}$ percentile tolerance limit is $0.90 \mathrm{pCi} / \mathrm{L}$.

\subsection{Total Uranium}

For the analytical methods comparison, paired results from datasets 2 and 3 (ID-TIMS and alpha spectrometry) were not significantly different using the Wilcoxon signed rank test ( $p$-value $=0.3$ ) for total uranium, thus, the data from the two methods were combined. The alpha spectrometry data from routine monitoring was non-normal (K-S p-value $<0.0001$ ), so a Kruskal-Wallis test was used to test the medians. The medians were similar across datasets for total uranium ( $\mathrm{p}$-value $=0.5)$, but the variances were not (Levene's p-value $=0.03$ ). Results from the ID-TIMS analysis from the five wells (dataset 5) were different than all the other datasets, so these 9 results were not combined with the rest. Four datasets (datasets $1-4$ ) were used to calculate the total uranium guideline concentration (Table 2). The upper 95\% confidence $95^{\text {th }}$ percentile tolerance limit for total uranium is $2.75 \mathrm{pCi} / \mathrm{L}$.

\section{CONCLUSIONS}

The datasets are assumed to represent uranium background based on the following evidence:

- $\quad$ Roback et al $(2000,2001)$ finds the measured ${ }^{238} \mathrm{U} /{ }^{235} \mathrm{U}$ ratios to be naturally occurring uranium and also finds no ${ }^{236} \mathrm{U}$, indicating that anthropogenic uranium contamination in the aquifer around the RWMC is unlikely, although other areas of the INEEL aquifer are potentially contaminated and

- $\quad$ there are no detectable temporal trends.

The results for total uranium, ${ }^{234} \mathrm{U}$, and ${ }^{238} \mathrm{U}$ from dataset 1 differ for groups of wells (Table 1). The three wells (M1S, M4D, and M10S) that have low concentrations are in a small spatial neighborhood south of the SDA. Three other wells in the area (USGS-89, USGS-117, and USGS-119) have low values, similar to the low-concentration group, but there are also six wells (USGS-87, USGS-120, OW-2, M17S, M6S, and M3S) in that same vicinity with higher values, similar to the overall mean concentration. The 
differences among wells should be monitored, but background levels for the RWMC monitoring area provided below should be used.

Datasets are combined to determine $95 \%$ confidence $95^{\text {th }}$ percentile tolerance limits. These guidelines are appropriate for the area within 10 miles of the RWMC. The upper tolerance limit for total uranium $(2.75 \mathrm{pCi} / \mathrm{L})$ is lower than the mean of $3 \mathrm{pCi} / \mathrm{L}$ reported by Knobel, Orr, and Cecil (1992), and much lower than the maximum value of $7 \mathrm{pCi} / \mathrm{L}$ reported in that study.

Determination of background status for ${ }^{235} \mathrm{U}$ could not be accomplished with the combined dataset since they represent two very different populations. Since there are significant differences between analytical measurement methods within the monitoring area, data cannot be combined to estimate background level. The ${ }^{235} \mathrm{U}$ alpha spectrometry data have a large uncertainty and a high detection limit compared to ID-TIMS, so distinguishing a background exceedance during routine aquifer monitoring would be difficult. The ID-TIMS is a more sensitive analytical method for ${ }^{235} \mathrm{U}$ and these low levels are not achievable by alpha spectrometry.

If an RWMC aquifer monitoring result exceeds the background guideline, defined as the $95 \%$ confidence 95 th percentile tolerance limit, then the values would be noted in the WAG 7 quarterly monitoring report and an investigation begun. The investigation might include assessment of (1) other isotope results, (2) analysis results for related compounds from that well, (3) results from other wells in the network, and (4) data from the previous quarter. Subsequent data from the well would be closely monitored, and the program would determine an appropriate course of action if the data start developing a trend.

\section{REFERENCES}

Holdren, K. Jean, Bruce H. Becker, Nancy L Hampton, L. Don Koeppen, Swen O. Magnuson, T. J. Meyer, Gail L. Olson, and Jeffrey Sondrup, 2002, Ancillary Basis for Risk Analysis of the Subsurface Disposal Area, INEEL/EXT-02-01125, Rev. 0, Idaho National Engineering and Environmental Laboratory.

Knobel, L. L., B. R. Orr, and L. D. Cecil, 1992, "Summary of Background Concentrations of Selected Radiochemical and Chemical Constituents in Groundwater from the Snake River Plain Aquifer, Idaho: Estimated from an Analysis of Previously Published Data," Journal of the Idaho Academy of Science, Vol. 28, X10.1, p. 48.

Olson, L. Gail, L. Don Koeppen, Alva M. Parsons, Paul D. Ritter, A. Jeffery Sondrup, 2003, FY 2002 Environmental Monitoring Report for the Radioactive Waste Management Complex, INEEL/EXT-03-00055, Rev.0, Idaho National Engineering and Environmental Laboratory.

Roback, R. C., 2002, "Initial Report for the Aquifer Background Study: Summary of Uranium and Plutonium Data for INEEL Groundwater Samples," INEEL/EXT-03-00655, Rev 0, Idaho National Engineering and Environmental Laboratory.

Roback, R. C., D. W. Efurd, M. T. Murrell, R. E. Steiner, and C. J. Duffy, 2000, “Assessment of uranium and plutonium in the saturated and unsaturated zones beneath the subsurface disposal area, INEEL," INEEL/EXT-01-00771, Rev 0, Idaho National Engineering and Environmental Laboratory. 
Roback, R. C., T. M. Johnson, T. L. McLing, M. T. Murrell, and S. L. Ku, 2001, "Uranium isotopic evidence for groundwater chemical evolution and flow patterns in the eastern Snake River Plain aquifer, Idaho," Geological Society of America Bulletin, 113: 1133 - 1141. 


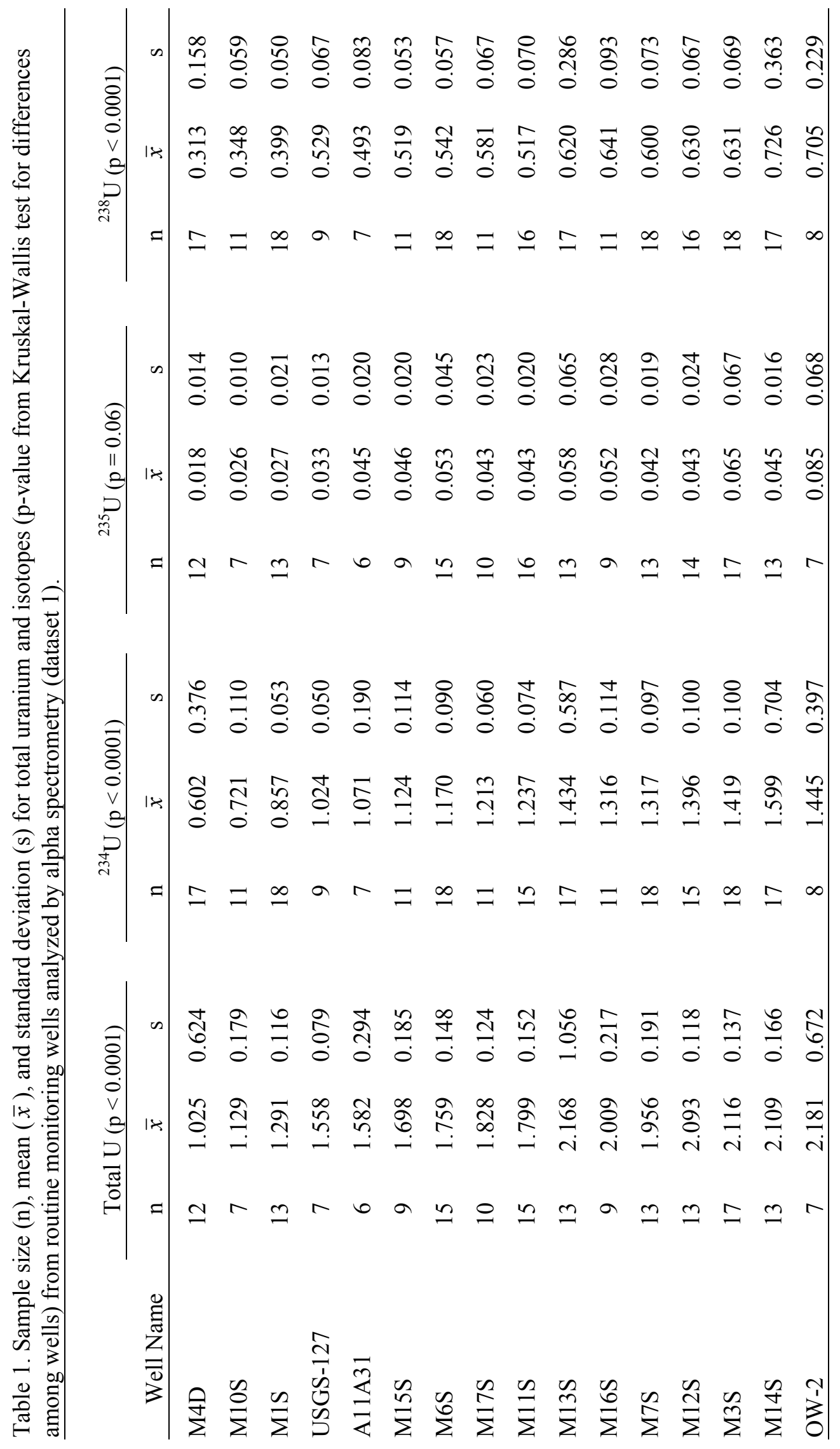




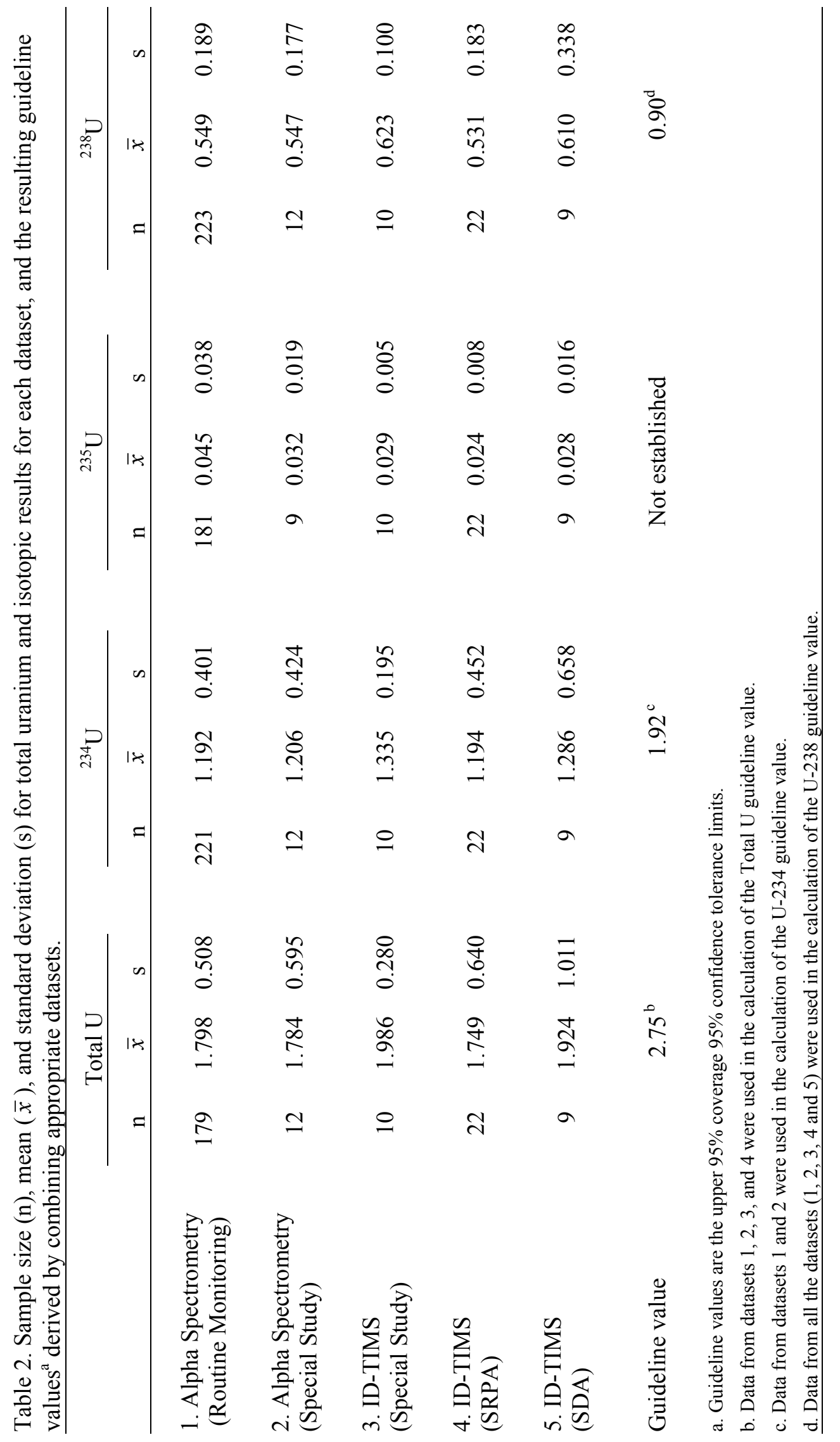




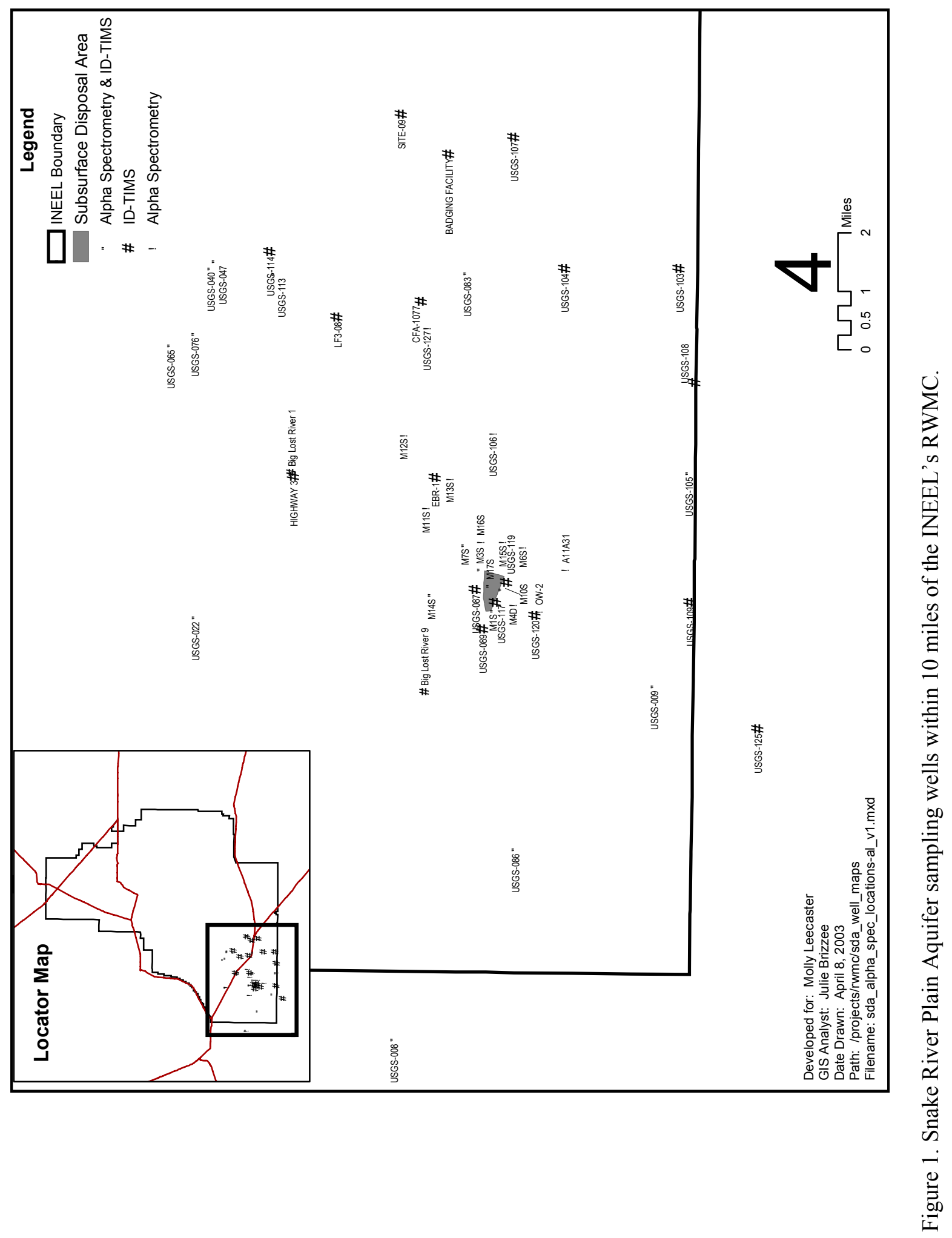



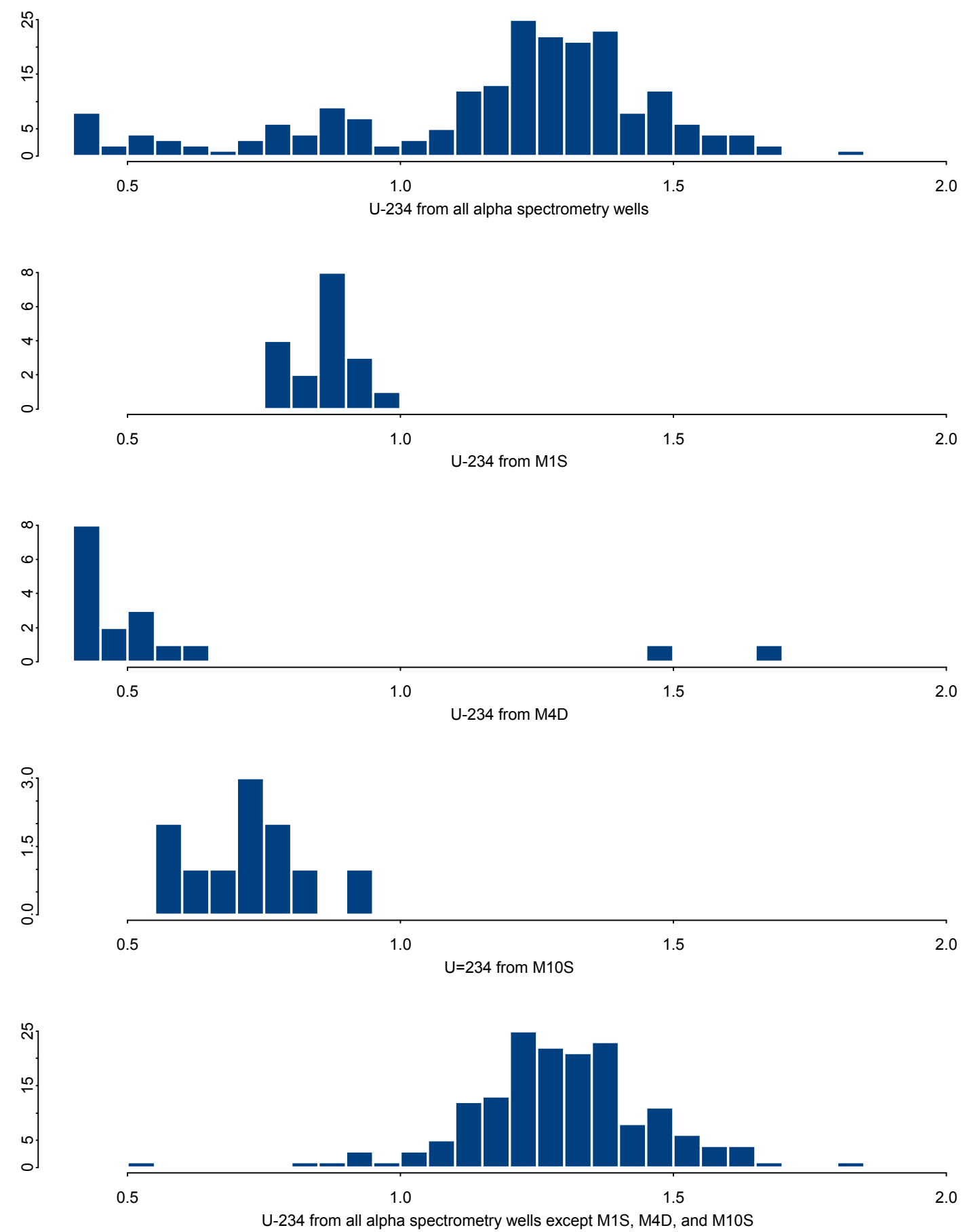

Figure 2. Distribution of ${ }^{234} U$ from alpha spectrometry. 

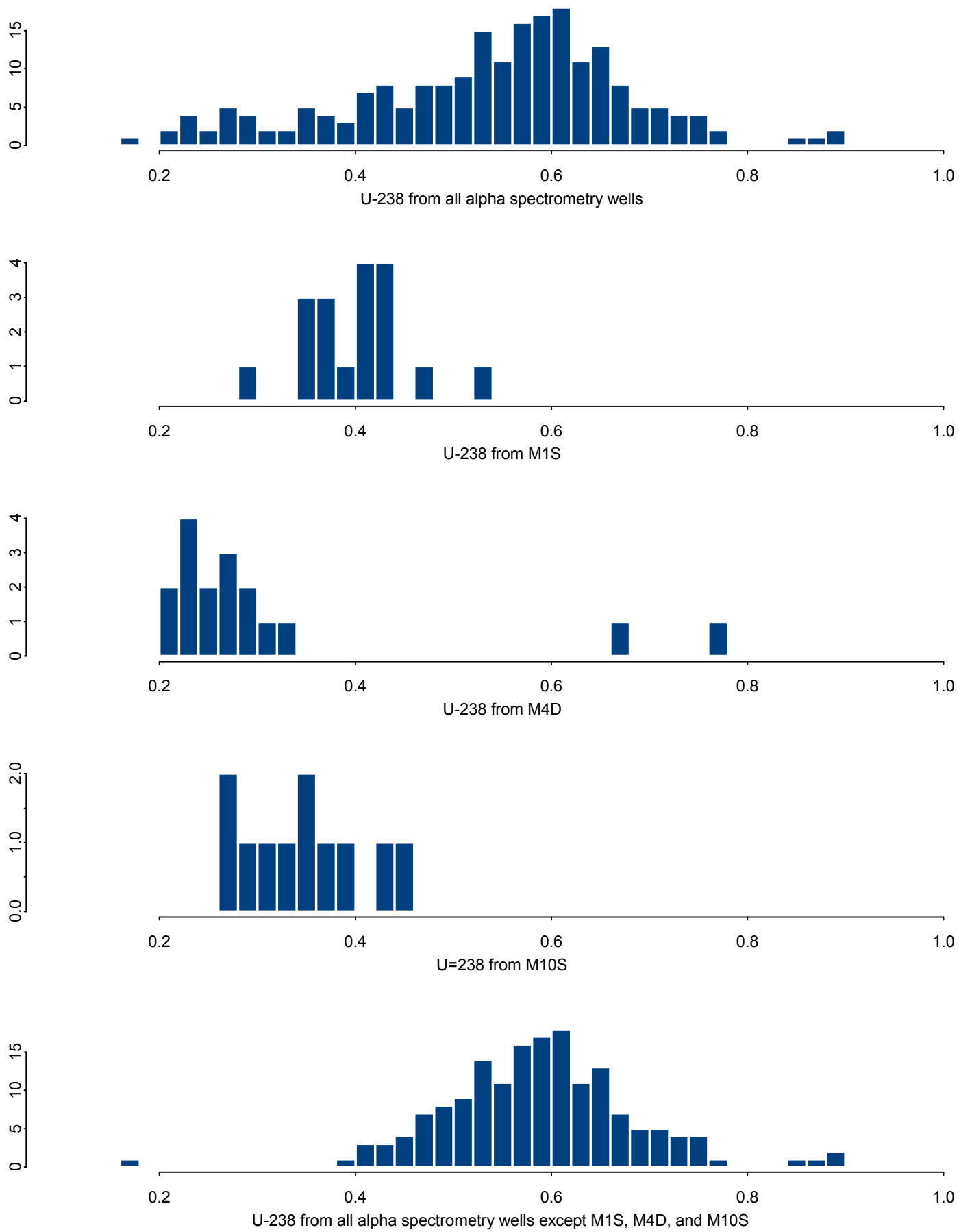

Figure 3. Distribution of ${ }^{238} \mathrm{U}$ from alpha spectrometry. 